\title{
Three-year follow-up of protection rates in children given varicella vaccine
}

\author{
David W Scheifele $M D^{1}$, Scott A Halperin $M D^{2}$, Francisco Diaz-Mitoma $M D^{3}$
}

DW Scheifele, SA Halperin, F Diaz-Mitoma. Three-year follow-up of protection rates in children given varicella vaccine. Can J Infect Dis 2002;13(6):382-386.

OBJECTIVE: To determine the rate and severity of subsequent varicella and zoster among children given a varicella vaccine. DESIGN: Retrospective survey conducted three years after vaccination, using standardized telephone interviews.

SETTING: Three urban Canadian centres (Halifax, Ottawa and Vancouver).

PARTICIPANTS: Of 475 eligible children, 431 aged three to 15 years participated.

INTERVENTION: Participants had received one dose of a live, attenuated varicella vaccine (Oka/GSK) an average of 36 months earlier.

MAIN OUTCOME MEASURES: Interviewers asked about known varicella exposures and obtained descriptions of any illnesses reported as varicella or zoster. Reported varicella was classified as definite (vesicles present, physician confirmation), probable (vesicles reported), suspected (nonvesicular rash, recent contact with varicella) or unlikely (nonvesicular rash, no known contact).

RESULTS: Parents reported 257 within-home exposures to varicella and alleged that 80 subjects had had varicella rash after exposure. Of these, 40 cases were classified as definite or probable (vesicles present; rate $9.3 \%$ or $3.1 \%$ per year on average), 31 as suspected (no vesicles; rate $2.4 \%$ per year) and nine as unlikely. All rash illnesses were mild: among children with vesicles, $75 \%$ were said to have up to 10 and none had more than 100 . The outcome of 76 exposures to household members with varicella was evaluable: 25 (32.9\%) resulted in a rash, and $13(17.1 \%)$ of those involved vesicles (maximum 40 lesions). Parents alleged that three subjects had zoster, but only one illness was definite (six vesicles, physician confirmed).

CONCLUSIONS: Varicella vaccination completely prevented the development of typical chickenpox during the three years of observation. Breakthrough infections were infrequent (about 5\% per year) and mild. Zoster was rare.

Key Words: Chickenpox; Prevention; Vaccine effectiveness; Varicella; Varicella vaccine

\section{Un suivi après trois ans du taux de protection chez les enfants ayant reçu le vaccin antivari- celleux}

OBJECTIF : Déterminer le taux et la gravité d'une varicelle ou d'un zona se déclarant chez des enfants ayant reçu un vaccin contre la varicelle. MÉTHODOLOGIE : Étude rétrospective menée trois ans après la vaccination, au moyen d'entrevues téléphoniques normalisées.

EMPLACEMENT : Trois centres canadiens urbains (Halifax, Ottawa et Vancouver).

PARTICIPANTS : Sur 475 enfants admissibles, 431 de trois à 15 ans ont participé.

INTERVENTION : Les participants avaient reçu une dose du vaccin antivaricelleux vivant atténué (Oka ou GSK) en moyenne 36 mois plus tôt.

PRINCIPALES MESURES D'ISSUE : Les enquêteurs ont posé des questions sur l'exposition connue à la varicelle et ont obtenu des descriptions de toute maladie déclarée comme la varicelle ou le zona. Les cas de varicelle déclarés étaient classés comme définitifs (présence de vésicules, confirmation par le médecin), probables (présence de vésicules), présumés (éruption non vésiculaire, contact récent avec la varicelle) ou improbables (éruption non vésiculaire, aucun contact connu).

RÉSULTATS : Les parents ont déclaré 257 expositions à la varicelle à la maison et ont allégué que 80 sujets avaient souffert d'une éruption varicelleuse après cette exposition. De ce nombre, 40 cas étaient classés comme définitifs ou probables (présence de vésicules, taux de 9,3\% ou de 3,1\% par année, en moyenne), 31 comme présumés (aucune vésicule, taux de 2,4\% par année) et neuf comme improbables. Toutes les maladies

Suite à la page suivante

${ }^{1}$ British Columbia's Children's Hospital, Vancouver, British Columbia; ${ }^{2} I W K$ Health Centre, Halifax, Nova Scotia; ${ }^{3}$ Children's Hospital of Eastern Ontario, Ottawa, Ontario

Correspondence: Dr David Scheifele, Director, Vaccine Evaluation Centre, Room L427, British Columbia's Children's Hospital, 4500 Oak Street, Vancouver, British Columbia V6H 3N1. Telephone 604-875-2422, fax 604-875-2635, e-mail dscheifele@cw.bc.ca

Received for publication August 3, 2001. Accepted January 23, 2002 
éruptives étaient bénignes : Parmi les enfants présentant des vésicules, $75 \%$ n'en avaient pas eu plus de 10 et aucun n'en avait eu plus de 100. L'issue de 76 expositions à des membres de la maisonnée atteints de la varicelle pouvait être évaluée : 25 (32,9 \%) ont entrâné une éruption et de ce nombre, 13 (17,1\%) s'associaient à des vésicules (maximum de 40 lésions). Les parents ont allégué que trois sujets avaient souffert de

Jaricella infection continues to be experienced by the majority of Canadian children despite licensure in 1998 of a varicella vaccine $(1,2)$. The principal barrier to vaccine utilization has been economic because most provinces do not yet offer the vaccine as part of their routine programs. Another barrier has been the perception among some parents and physicians that varicella is a mild illness, not worth preventing $(2,3)$. Published descriptions of the costs and morbidity attributed to varicella at paediatric centres across Canada $(2,4-7)$ put the issue of disease severity into clearer perspective. Some physicians remain uncertain about the effectiveness of the varicella vaccine $(2,3)$. It is unlike other familiar viral vaccines in that it fails to prevent infection in $10 \%$ to $30 \%$ of recipients (1), but these 'breakthrough' infections are mild and often barely recognizable as varicella. Vaccination with the live, attenuated varicella vaccine may later result in zoster $(1,8)$, although reports to date indicate that the risk is lower than after natural infection, and the clinical course is mild $(8,9)$.

In 1997 we (10) assessed the safety of an Oka-strain varicella vaccine (Oka/GSK) (Varilrix, GlaxoSmithKline, Belgium) (11) that was subsequently licensed in Canada. This product will be marketed in late 2002, on expiry of distribution limitations among manufacturers using the Oka vaccine virus. The Oka/GSK varicella vaccine is not substantially different from the Oka-strain varicella vaccine (Oka/Merck) (Varivax, Merck Frosst, Canada) currently available to prescribers (1). In the present report, we describe the results of a three-year follow-up of children given $\mathrm{Oka} / \mathrm{GSK}$ varicella vaccine regarding their experiences with varicella and zoster.

\section{PATIENTS AND METHODS}

Efforts were made to contact the parents of 475 children who had been given one dose of Oka-strain varicella vaccine (Varilrix) three years previously in a vaccine safety study conducted in Halifax, Ottawa and Vancouver (10) Children were aged 12 months to 12 years at vaccination. Not included were 14 subjects who proved to be seropositive before vaccination, one subject who did not complete the original study and 15 subjects who developed varicellalike rashes within six weeks after vaccination, among the original enrolment of 505 children (10). Participants did not undergo postimmunization serological tests.

Parents were initially sent an invitation letter to participate in a telephone interview about their child's experiences with varicella since the vaccination. Families that had changed address were located through their family doctor or were excluded if they could not be located. Interviewers obtained verbal consent from the parent zona, mais seulement une maladie était définitive (six vésicules, cas confirmé par un médecin).

CONCLUSIONS : La vaccination antivaricelleuse a entièrement prévenu l'apparition d'une varicelle caractéristique pendant les trois ans d'observation. Les infections ayant percé étaient peu courantes (environ $5 \%$ par année) et légères. Le zona était rare.

before proceeding, emphasizing the voluntary nature of the interview. Interviews were structured to elicit details about known exposures to others with varicella or zoster and any such illnesses in the child. The period of risk after exposure to varicella was defined as one to three weeks, drawing on the parents' best approximation. In assessing alleged breakthrough cases of varicella, the following were particularly noted: whether the source case had been confirmed by a physician; whether the subject's rash involved vesicles; and whether the rash had been evaluated by a physician. In the latter instance, permission was sought to obtain details from the physician's records. Interviewers assessed the nature and severity of potential breakthrough infections in terms of number and type of skin lesions, associated signs and symptoms, any complications or need for corrective therapy, and outcome, including apparent transmission to another person. Interviewers made a particular effort to distinguish vesicular rashes (described to parents as small blisters) from macular or papular rashes (described to parents as red spots or raised bumps). Information was recorded in a specific case report form, which was centrally audited for completeness before being entered into an electronic database (Access, Microsoft Corporation, USA).

The following classification was applied to breakthrough cases of varicella:

- Definite: skin lesions included vesicles and diagnosis was confirmed by a physician, or the child had been in recent contact (within three weeks) with a physician-confirmed case of varicella.

- Probable: skin lesions reportedly included vesicles.

- Suspected: skin lesions were described as nonvesicular, but the child had recent contact with a case of varicella or appeared to transmit a varicellalike illness to a contact.

- Unlikely: skin lesions were nonvesicular and there was no other epidemiological evidence.

Zoster cases required physician confirmation and were considered to be definite with vesicles and suspected with nonvesicular skin lesions. Any other scenario was coded as unlikely.

The study was reviewed and approved by the research ethics board of each participating centre.

\section{RESULTS}

Parents of 431 children (90.7\%) agreed to participate, 156 in Halifax, 124 in Ottawa and 151 in Vancouver. Participation rates were similar among the centres. Current age of subjects ranged from three to 15 years: 369 (85.6\%) 
TABLE 1

Exposure histories of subjects with and without reported varicella infection

\begin{tabular}{|c|c|c|c|c|}
\hline & \multirow[b]{2}{*}{ No varicella reported } & \multicolumn{2}{|c|}{ Varicella infection reported } & \multirow[b]{2}{*}{ Total } \\
\hline & & Varicella illness & $\begin{array}{l}\text { Previous exposure } \\
\text { without infection }\end{array}$ & \\
\hline Number of subjects & 348 & 80 & NA & 431 \\
\hline \multicolumn{5}{|l|}{ Household exposure to varicella: } \\
\hline Subjects & 39 & 25 & 6 & 64 \\
\hline Instances & 45 & 25 & 6 & 76 \\
\hline Household exposure to zoster & 10 & 1 & 0 & 11 \\
\hline \multicolumn{5}{|l|}{ Home visitors with varicella: } \\
\hline Subjects exposed & 60 & 38 & 10 & 98 \\
\hline Instances & 114 & 38 & 19 & 171 \\
\hline \multicolumn{5}{|l|}{ Total known exposures } \\
\hline Subjects & 109 & 64 & 16 & 173 \\
\hline Instances & 169 & 64 & 25 & 258 \\
\hline
\end{tabular}

NA Not applicable

were five years of age or older. Only 68 children (15.8\%) had not attended childcare or school since the vaccination. The mean interval since vaccination was 36 months (range 34 to 40 months). The mother provided information in $92 \%$ of interviews. Although 33 children $(7.7 \%)$ had a chronic illness needing long term medication, none was immunosuppressed. The 431 subjects had a total of 620 children and 909 adults residing with them. Of these, 10 adults $(1.1 \%)$ and 368 children $(59.4 \%)$ had received varicella vaccine, and 747 adults $(82.2 \%)$ and 105 children $(16.9 \%)$ had a history of varicella infection before the subject received varicella vaccine. The high vaccination rate resulted from the opportunity for multiple siblings to participate in the original study.

Parents indicated that 348 subjects $(80.7 \%)$ had no illnesses resembling varicella or zoster during the follow-up period. Forty-nine of those subjects $(14.0 \%)$ had been exposed to a household member with varicella (39) or zoster (10) (Table 1). Exposures occurred throughout the three-year period with the largest number (21) occurring in the third year. Four children were exposed twice and one child three times to household members with varicella. Sixty subjects were exposed on 114 occasions to household visitors who had varicella or developed it shortly afterward. Other contacts were not enumerated.

Parents alleged that 80 subjects $(18.6 \%)$ had varicella and three subjects $(0.7 \%)$ had zoster during the follow-up period (Table 2). Fifteen varicella episodes occurred during the first year after vaccination, 31 during the second and 34 during the third. On the basis of the available information, 22 cases of varicella were classified as definite and 18 as probable, with each child having one or more vesicles. In 31 other cases, varicella was classified as suspected on the basis of recent exposure, but the rash was nonvesicular. Ten reports were considered unlikely, including one alleged instance of zoster. One episode of zoster (rate $0.2 \%$ ) was classified as definite (vesicles present, physician confirmed) and one as suspected (physician diagnosis, nonvesicular rash). Thus, the frequency of definite or probable varicella

\section{TABLE 2}

Incidence rates of alleged varicella among vaccinated children

\begin{tabular}{|c|c|c|}
\hline & Total & $\begin{array}{r}\text { Three-year } \\
\text { rate (\%) }\end{array}$ \\
\hline \multicolumn{3}{|l|}{ Varicella cases } \\
\hline $\begin{array}{l}\text { Definite } \\
\text { (vesicles present, physician confirmation) }\end{array}$ & 22 & 5.1 \\
\hline $\begin{array}{l}\text { Probable } \\
\text { (vesicles present) }\end{array}$ & 18 & 4.2 \\
\hline $\begin{array}{l}\text { Suspected } \\
\text { (exposure, nonvesicular rash) }\end{array}$ & 31 & 7.2 \\
\hline $\begin{array}{l}\text { Unlikely } \\
\text { (no known exposure, nonvesicular rash) }\end{array}$ & 9 & 2.1 \\
\hline Subtotal & 80 & 18.6 \\
\hline \multicolumn{3}{|l|}{ Zoster cases } \\
\hline $\begin{array}{l}\text { Definite } \\
\text { (vesicles present, physician confirmed) }\end{array}$ & 1 & 0.2 \\
\hline $\begin{array}{l}\text { Suspected } \\
\text { (physician diagnosis, no vesicles) }\end{array}$ & 1 & 0.2 \\
\hline $\begin{array}{l}\text { Unlikely } \\
\text { (no physician examination, no vesicles) }\end{array}$ & 1 & 0.2 \\
\hline Subtotal & 3 & 0.7 \\
\hline
\end{tabular}

infection (40 cases) was $9.3 \%$ over 36 months or $3.1 \%$ per year on average, while that of suspected varicella (nonvesicular rash, 31 cases) was $7.2 \%$ over 36 months or $2.4 \%$ per year. The rate of definite zoster was one per 15,516 child-months of observation.

Rash illnesses alleged to be varicella were generally mild. The average duration of rash was less than five days; $90 \%$ resolved within a week. Rash was distributed over the trunk (89.0\%), head $(50.5 \%)$, legs $(31.7 \%)$, arms $(29.3 \%)$ and mouth $(3.7 \%)$. Parents estimated the number of rash elements at fewer than 50 in $88.0 \%$. Among patients with vesicles, $75 \%$ reportedly had no more than 10 such lesions. The child with the largest number of reported vesicles 
(about 100) had no fever or activity impairment. Parents said that six children $(7.2 \%)$ were confined to bed for a time. Parents recalled fever in $31 \%$ of illness episodes. Medical attention was sought for 26 rash illnesses (32.1\%). One child was treated with oral acyclovir out of concern regarding an underlying illness (cystic fibrosis) but suffered no complication. The only reported complications involved minor skin scarring in two children who had no more than 12 vesicles each.

All three alleged instances of zoster involved the trunk and were mild, including the one confirmed case (up to 50 lesions and about six vesicles, lasting seven days). One suspected case with a patch of papules but no vesicles resulted in mild skin discolouration. The confirmed and suspected cases occurred 31 and 34 months after vaccination, respectively.

Among the 80 alleged varicella cases, a source case was known to parents in 64 instances $(80 \%)$ (Table 1). The source case was in a household member in 25 instances. Exposures involved varicella in every instance but one. The source illness was diagnosed as varicella by a physician in 28 instances (43.8\%). Parents estimated the interval between exposure and onset of rash in the subject at three weeks or less in $96.2 \%$ of cases. Rash illness in the subject reportedly spread to a sibling or other child in 15 instances, within an estimated two weeks in 14 instances. Secondary illnesses were considered to be mild by parents in 12 instances, but the immunization history of affected children was not ascertained (some were known to have been vaccinated).

Among the 80 alleged cases, six earlier exposures to household varicella cases were reported that did not result in apparent infection of the subject (Table 1). Ten subjects had been exposed on 19 occasions to household visitors who had varicella, without infection developing.

The outcome of 76 reported exposures to household members with varicella was evaluable: $25(32.9 \%)$ resulted in a rash illness, 13 (17.1\%) involving vesicles. The maximum number of vesicles reported was 40 ; half had no more than 10 lesions. In half of the patients with vesicles, either the current illness (four) or the source case (three) was confirmed as varicella by a physician. No apparent transmission occurred in 51 instances $(67 \%)$. The proportion of exposures that resulted in rash did not differ by year of observation following immunization (for example, $38.9 \%$ during year one, $36.0 \%$ during year three).

\section{DISCUSSION}

Our observations indicate that there is a high level of protection following varicella vaccination with the Oka/GSK product (11). During three years of observation involving over 250 recognized exposures to varicella within the home, none of our subjects developed typical chickenpox. This is consistent with other evaluations of Oka-based vaccines $(9,12-18)$. However, as expected with such vaccines, some subjects developed mild breakthrough infections. Among those exposed to a household member with varicella, the reported rate of infection was 33\%, although only half of these rashes (17\%) involved vesicles, with up to 40 such lesions. In contrast, among susceptible children exposed to household cases, the expected rate of secondary infection approximates $90 \%$, with rash involving an average of 500 vesicles $(19,20)$. The rate of breakthrough infection after household exposure in other studies was $4 \%$ with the original Oka vaccine (21), $5 \%$ to $13.5 \%$ with the Oka/Merck vaccine $(15,22,23)$ and $36 \%$ with Oka/GSK (17). Our report is consistent with the previous evaluation of the Oka/GSK vaccine (17). The differences in reported rates of breakthrough infection may relate to differing vaccine potency, because the initial antibody concentration is a strong determinant of protection rate $(14,24,25)$, as well as to different methods of ascertainment. The rate of breakthrough infection after household exposure is the most severe test of protection after vaccination, whereas the overall rate of breakthrough infection is not adjusted for exposure rates or types. With that limitation in mind, we observed an average annual rate of breakthrough infection of $3.1 \%$ for rashes with vesicles and $5.5 \%$ overall, consistent with other reports $(9,14,15,18,22,23)$, most of which reported breakthrough infection rates of $2 \%$ to $3 \%$ per year

A noteworthy feature of breakthrough varicella infections is their mildness relative to natural infection. Our report is consistent with the published literature $(8,14$ $18,25,26)$ in this regard. Only half of the alleged varicella infections in our study involved vesicular rash elements, and, in most instances, 10 or fewer vesicles were present. A modified rash involving only macules or maculopapules is not recognizable as varicella, so we only classified such cases as breakthrough infections when the epidemiological context supported the diagnosis; that is, the child was in recent contact with a typical case or transmitted infection to someone who developed vesicles. The possibility remains in the absence of serological confirmation of the diagnosis that some cases had other causes (such as enteroviral handfoot-mouth syndrome) or that the epidemiological associations were coincidental or based on incorrect diagnoses. The net effect would have been to overestimate the rate of breakthrough infections. In a prospective study of breakthrough infections (27), $15 \%$ of clinically diagnosed cases were not serologically confirmed.

Similar limitations apply to the diagnosis of zoster. In keeping with other reports $(8,9,15)$, in our one definite case the child had mild disease, with only six vesicles. In a second case, localized nonvesicular rash was labelled as zoster by a physician but with no supporting evidence of the etiology. A third report involved no vesicles or physician assessment and was considered unlikely. The one definite case of zoster reflects a rate of 7.7 per 10,000 child-years of observation. The rate observed by Black et al (9) in a postmarketing study of nearly 90,000 vaccinees was 1.5 per 10,000 person-years, using a similar case definition but a different Oka strain vaccine.

The retrospective nature of our study has inherent weaknesses. Parents were not forewarned to make detailed observations or notes about lesion types and numbers or intervals 
between exposure and illness onset. Interviewers used the term 'blisters' in lieu of vesicles for clarity, because these are distinctive hallmarks of varicella and zoster. Estimates of lesion numbers and other illness components should be interpreted cautiously because parents may have tended to minimize in the absence of specific recollections. Because rash illnesses were mild, relatively few were assessed by physicians. None was confirmed by virus isolation or serological testing. Some of the subjects were siblings, a fact that might have minimized the observed rate of breakthrough infections after household exposure because patients with mild cases are less likely to transmit infection to close contacts (16). We did not ascertain the severity of source cases.

Allowing for the limitations, our study confirms that vaccination with $\mathrm{Oka} / \mathrm{GSK}$ varicella vaccine prevents subsequent development of typical chickenpox and rarely results in zoster. Breakthrough infections do occur, especially after household exposure, but are mild and potentially difficult to recognize as varicella. Nevertheless, parents still sought medical advice for one-third of rash illnesses despite their mild nature. If this remains true of parents in the future, despite better counselling, and if rash illnesses continue to occur in about $5 \%$ of children during each addi-

\section{REFERENCES}

1. National Advisory Committee on Immunization. Statement on the recommended use of varicella virus vaccine. Can Commun Dis Rep 1999;25(ACS-1):1-16.

2. Law BJ. Towards universal childhood immunization against chickenpox? Pediatr Child Health 2000;5:262-6.

3. Newman RD, Taylor JA. Reactions of pediatricians to the recommendation for universal varicella vaccination. Arch Pediatr Adolesc Med 1998;152:792-6.

4. Kuhn S, Davies HD, Jadavji T. Varicella zoster virus infections in Canadian children in the prevaccine era: a hospital-based study. Can J Infect Dis 1997;8:323-8.

5. Law B, Fitzsimon C, Ford-Jones L, et al. Cost of chickenpox in Canada: Part 1. Cost of uncomplicated cases. Pediatrics 1999;104:1-6.

6. Law B, Fitzsimon C, Ford-Jones L, et al. Cost of chickenpox in Canada: Part II. Cost of complicated cases and total economic impact. Pediatrics 1999;104:7-14.

7. Laupland KB, Davies HD, Low DE, et al. Invasive group A streptococcal disease in children and association with varicella-zoster virus infection. Pediatrics 2000;105:e60.

8. Sharrar RG, La Russa P, Galea SA, et al. The postmarketing safety profile of varicella vaccine. Vaccine 2001;19:916-23.

9. Black S, Shinefield H, Ray P, et al. Postmarketing evaluation of the safety and effectiveness of varicella vaccine. Pediatr Infect Dis J 1999;18:1041-6.

10. Diaz-Mitoma F, Halperin SA, Scheifele D. Reactogenicity to a live attenuated varicella vaccine in Canadian children. Can J Infect Dis 2000;11:97-102.

11. Meurice F, De Bouver JL, Vandevoorde D, Woods S, Bogaerts H. Immunogenicity and safety of a live attenuated varicella vaccine (Oka/SB Bio) in healthy children. J Infect Dis 1996;174 (Suppl 3):S324-9.

12. Izurieta HS, Strebel PM, Blake PA. Postlicensure effectiveness of varicella vaccine during an outbreak in a child care center. JAMA 1997;278:1495-9.

13. Clements DA, Moreira SP, Coplan PM, Bland CL, Walter EB. Postlicensure study of varicella vaccine effectiveness in a day-care setting. Pediatr Infect Dis J 1999;18:1047-50.

14. Clements DA, Armstrong CB, Ursano AM, Moggio MM, Walter EB, Wilfert CM. Over 5-year follow-up of Oka/Merck varicella vaccine recipients in 465 infants and adolescents. Pediatr Infect tional year after vaccination, then routine vaccination will be less cost effective than was generally estimated (28).

The potential for breakthrough infection is one of the most distinctive features of current varicella vaccines and bears emphasis when describing vaccine effectiveness to parents and providers alike. During the first few years after vaccination, children with the lowest antibody responses to the vaccine were most likely to experience breakthrough infection with exposure, while those with stronger responses were well protected (25). However, after breakthrough infection, children develop strong antibody responses (16) that may contribute to long term protection. More extended follow-up is needed to determine the rates of breakthrough infection over longer intervals after vaccination and with larger proportions of vaccinated children in the population, because the latter will reduce exposures to natural infection.

ACKNOWLEDGEMENTS: This study was supported by a grant in aid of research provided by GlaxoSmithKline. We are grateful to Nick Radojevic and Jim Parsons of SKB Pharma for their support. D Scheifele is a Career Investigator of the BC Research Institute for Children's and Women's Health.

Dis J 1995;14:874-9.

15. Kuter BJ, Weibel RE, Guess HA, et al. Oka/Merck varicella vaccine in healthy children: Final report of a 2-year efficacy study and 7-year follow-up studies. Vaccine 1991;9:643-7.

16. Watson BM, Piercy SA, Plotkin SA, Starr SE. Modified chickenpox in children immunized with the $\mathrm{Oka} /$ Merck varicella vaccine. Pediatrics 1993;91:17-22.

17. Lim YJ, Chew FT, Tan AYS, Lee BW. Risk factors for breakthrough varicella in healthy children. Arch Dis Child 1998;79:478-80.

18. Varis T, Vesikari T. Efficacy of high-titer live attenuated varicella vaccine in healthy young children. J Infect Dis 1996;174 (Suppl 3):S330-4.

19. Ross AH. Modification of chickenpox in family contacts by administration of gamma globulin. N Engl J Med 1962;267:369-76.

20. Balfour HH, Kelly JM, Suarez CS, et al. Acyclovir treatment of varicella in otherwise healthy children. J Pediatr 1990;116:633-9.

21. Asano Y, Nagai T, Miyata T, et al. Long-term protective immunity of recipients of the OKA strain of live varicella vaccine. Pediatrics 1985;75:667-71.

22. Johnson CE, Stancin T, Fattlar D, Rome LP, Kumar ML. A long-term prospective study of varicella vaccine in healthy children. Pediatrics 1997;100:761-6.

23. White CJ, Kuter BJ, Hildebrand CS, et al. Varicella vaccine (VARIVAX) in healthy children and adolescents: results from clinical trials, 1987 to 1989. Pediatrics 1991;87:604-10.

24. Johnson C, Rome LP, Stancin T, Kumar ML. Humoral immunity and clinical reinfections following varicella vaccine in healthy children. Pediatrics 1989;84:418-21.

25. White CJ, Kuter B, Ngai A, et al. Modified cases of chickenpox after varicella vaccination: correlation of protection with antibody response. Pediatr Infect Dis J 1992;11:19-23.

26. Vazquez M, La Russa PS, Gershon AA, Steinberg SP, Freudigman K, Shapiro ED. The effectiveness of the varicella vaccine in clinical practice. N Engl J Med 2001;344:955-60.

27. Bernstein HH, Rothstein EP, Watson BM, et al. Clinical survey of natural varicella compared with breakthrough varicella after immunization with live attenuated $\mathrm{Oka} /$ Merck varicella vaccine. Pediatrics 1993;92:833-7.

28. Lieu TA, Cochi SL, Black SB, et al. Cost-effectiveness of a routine varicella vaccination program for US children. JAMA $1994: 271: 375-81$ 


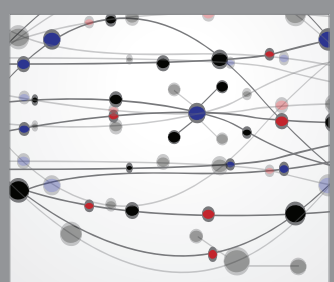

The Scientific World Journal
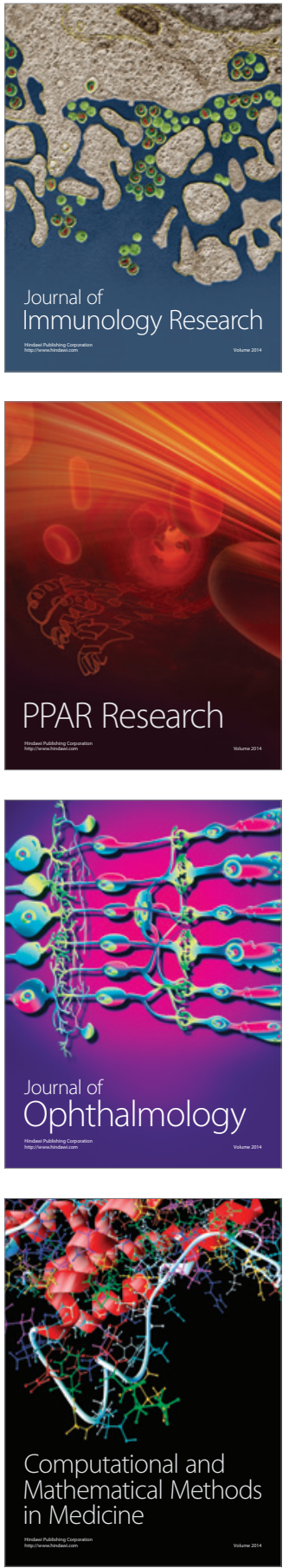

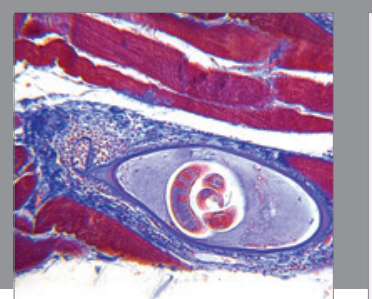

Gastroenterology Research and Practice

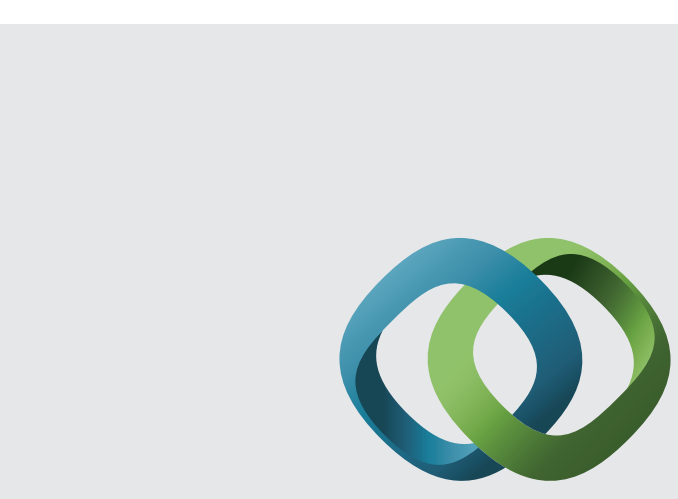

\section{Hindawi}

Submit your manuscripts at

http://www.hindawi.com
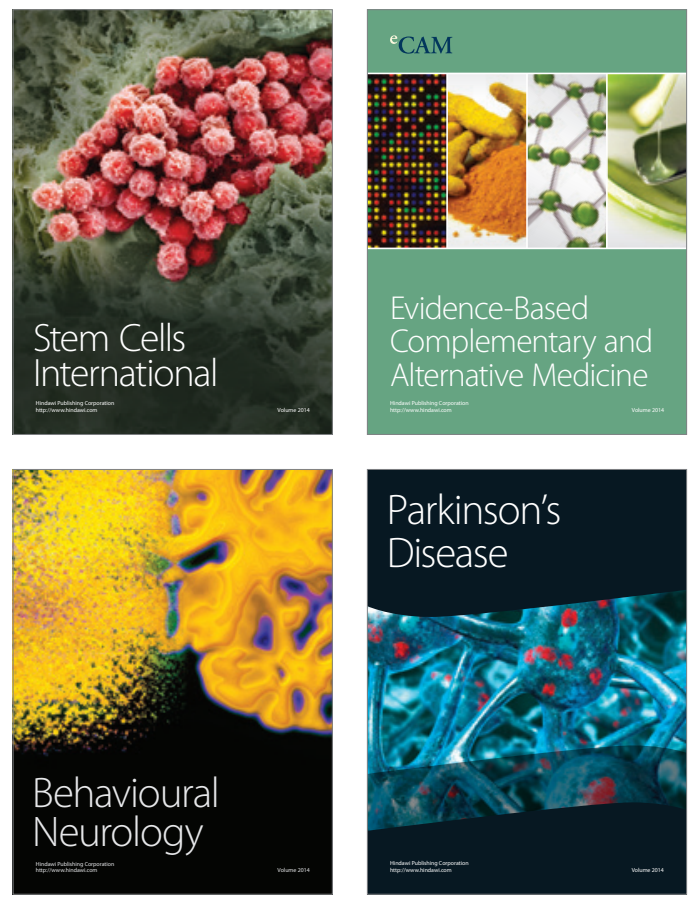
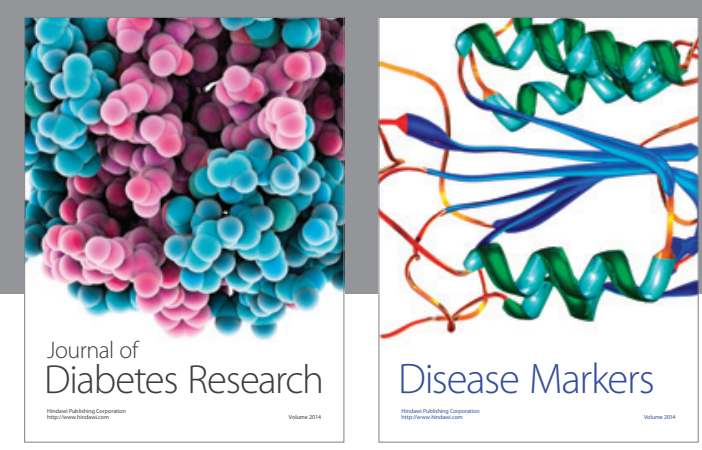

Disease Markers
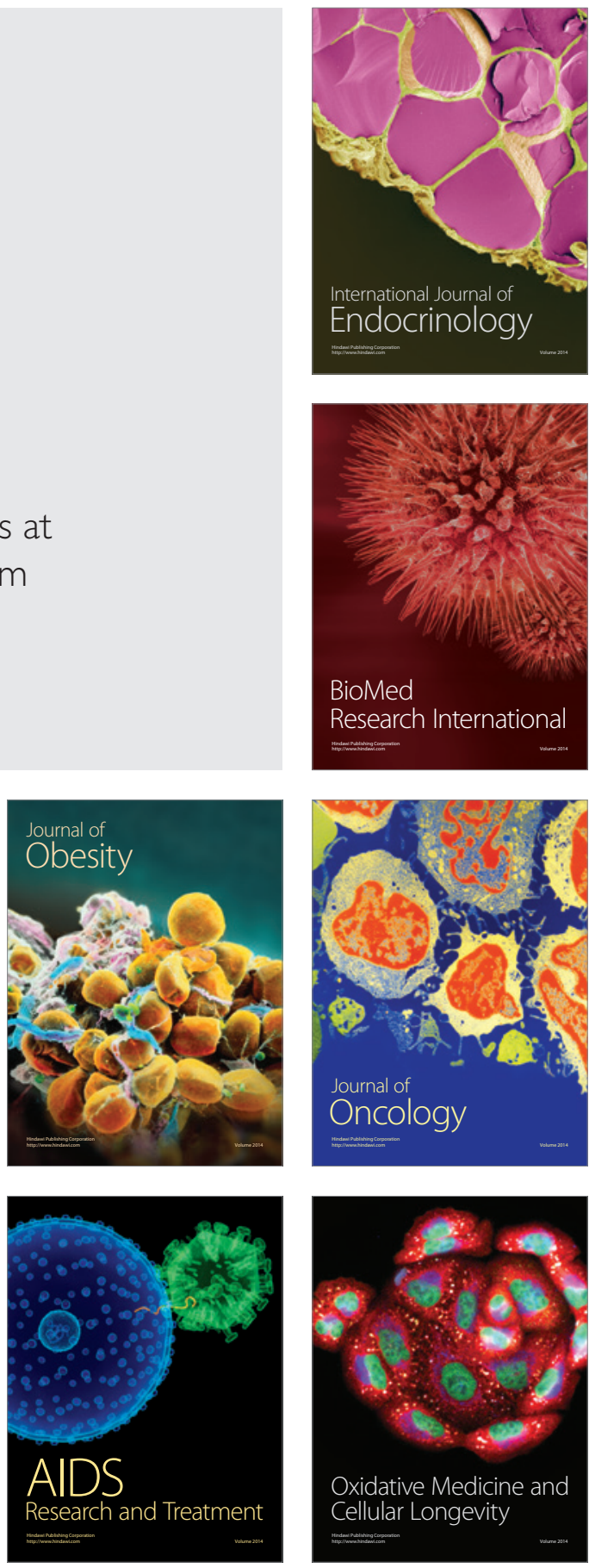